\title{
Ring Rolling speed rolls optimization to improve ring quality and reduce production time
}

\author{
G. Allegri $1^{*}$ and L. Giorleo ${ }^{1}$ \\ ${ }^{1}$ Department of Mechanical and Industrial Engineering, University of Brescia, 25123 Brescia, Italia. \\ Phone: +390303715522; Fax: +390303702448
}

ABSTRACT - In this paper, an analysis of the production time reduction as a function of the Idle and Axial rolls speed law in a Ring Rolling process was examined. Starting from an industrial case study, the authors defined a new milling curve able to produce a better ring quality with lower loads. From this result, the authors tested the effect of the production time reduction till the $40 \%$ of the initial one. The Ide roll velocity was varied in a range between 0.71 and $1.13 \mathrm{~mm} / \mathrm{s}$ while the Axial roll between 0.35 and $1.70 \mathrm{~mm} / \mathrm{s}$. Geometrical and load parameters have been taken into account to compare the results achieved. The authors identified in the external ring diameter and in the Idle roll maximum load the most critical parameter to control; in particular, a break-even point was determined in order to select a set of rolls speed laws able to produce a good quality ring with lower production time (about 20\%) and lower loads (about $10 \%$ ). In this research both experimental and numerical approaches were followed.

\author{
ARTICLE HISTORY \\ Revised: $3^{\text {rd }}$ Sept 2019 \\ Accepted: $4^{\text {th }}$ Sept 2019 \\ KEYWORDS \\ Ring rolling; \\ milling curve; \\ process optimization; \\ FEM.
}

\section{INTRODUCTION}

Ring Rolling is an advanced local incremental forming technology used to fabricate precise seamless ring-shape parts with different dimensions and materials. In this process, the metal is rolled between two couples of rolls: two axial and two radial. In each couple one roll moves towards the other one to continuously reduce the ring height and width; due to volume constancy, a diameter expansion occurs. The Ring Rolling process is used in the production of railway wheels, anti-friction bearing and different ring-shaped workpieces for automotive, aerospace and wind industry applications [1]. It can be both a hot or cold process and different alloys such as steels, light alloys and titanium can be worked. The advantages of Ring Rolling process include short production time, uniform quality, close tolerances and considerable savings in material cost. This process, compared to others as casting or plasma cutting, can guarantee lower working temperatures, less required material and, consequently, a reduction in energy consumption. Moreover, the main advantage of the workpieces produced by Ring Rolling, compared to other technological processes, is given by the size and orientation of the grains, especially on the worked surface which give to the final product excellent mechanical properties [2].

Figure 1 summarizes a scheme of the Ring Rolling process: An Idle roll forces a hollow circular preform against a Driver roll on the Y direction. At the same time, the Axial rolls applies pressure in Z direction. Moreover, a backward movement on the $\mathrm{Y}$-axis is added to the Axial rolls according to the diameter expansion. Because the ring does not rotate on its own axis, two Guide rolls are designed to help the stability of the process. Therefore, in a Ring Rolling process the following parameters must be defined.

The Idle roll speed profile along the $\mathrm{Y}$ direction and the Axial roll speed profile along the $\mathrm{Z}$ directions to control the ring cross section; the Driver roll angular velocity that must be set accordingly to Idle and Axial roll speed profiles to avoid excessive ring deformation in the cross section; the Axial roll speed profile along the Y direction accordingly to the ring expansion; the Guide rolls speed profile to help the process stability. 


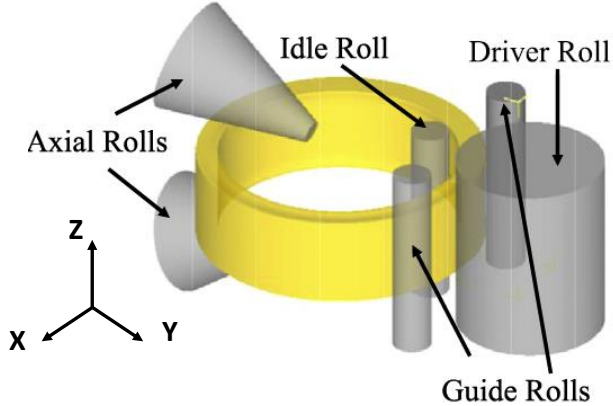

Figure 1. Ring Rolling scheme.

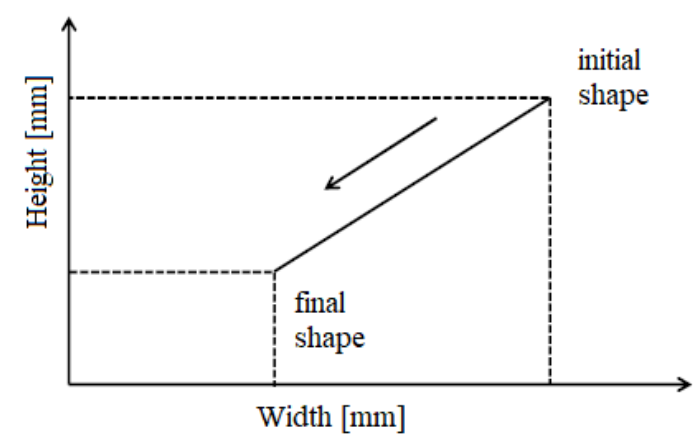

Figure 2. Milling curve for a ring rolling process.

Since each roll displacement can be set independently from the others, it is normal, in industrial practice, to introduce the so-called milling curve as a function of Idle roll Y-speed and Axial roll Z-speed. This curve correlates the instantaneous ring height $(\mathrm{H})$ and width $(\mathrm{W}$ that is defined as the difference between the external radius and the internal radius of the ring) (Figure 2). In Ring Rolling, the milling curve is fundamental to guarantee a correct ring production; moreover, it has been demonstrated how, by imposing an optimized curve, it is possible to reduce rolls load and production time while ensuring a correct ring geometry avoiding the fishtail defect [3].

In literature, different scientific works are available on this process and focusing their attention on the influence of process parameters; in particular, the rolls geometry, the tools motion and the process virtualization are relevant topics of the ongoing researches. About the rolls geometry, the size effect of rolls in radial-axial Ring Rolling has been studied by Zhou [4] using FE simulation, starting from the obtained results Salem [5] introduced a novel approach in modeling of Guide and Axial rolls used in the Radial-Axial Ring Rolling process. Giorleo [6] focused the research evaluating the preform geometry influence on an industrial Ring Rolling process; the results showed that a decrease of the starting preform ring height could guarantee less energy and loads, less defects and material saving. Zhu [7] investigated different geometries and ring dimensions to find optimal blank design principle for Axial-section in Ring Rolling. The effect of initial blank temperature was analyzed by $\mathrm{Ng}$ [8] while the forming limit by Mianroodi [9] in case of mild steel.

About the tool motion, interesting results have been achieved by Lin [10] that introduced the extremum Idle roll feeding speed needed to ensure a correct ring rotation and diameter expansion. Yan [11] proposed a relationship to correlate the Idle roll speed to the ring outer diameter grown rate in case of cold Ring Rolling. Anjami et al. [12] focused their research in finding the effect of constant and variable feed speeds. Starting from the hypothesis to impose a ring growing with a constant velocity Guo L. [13] presented a steady forming condition for radial-axial Ring Rolling. A new method of adaptive movement control of guide and conical rolls is proposed by Peng [14] where the movement is established combining the node track method in an FE model. Zhou [15] analyzed the effects of axial rolls motions on radial-axial rolling process for large-scale alloy steel ring; the research results provide valuable guidelines for the motion control of the Axial rolls. Li [16] suggested a guideline for planning the feed rates of the relevant complex profiled Ring Rolling process to improve efficiency and reduce cost. A correlation between the feed rate and the surface roughness of the produced workpiece was analyzed by Mohanty [17].

Recently, different authors are adopting the Ring Rolling virtualization approach to optimize the process: Jenkouk [18] designed a closed-loop control to monitor the process parameters (rotations, feed rates, guide rolls) in real time, considering the machine's performance limits as well as the process evolution. Xiao [19] investigated on a multi-response optimization design for the forming parameters of opened-pass plain cold Ring Rolling process to obtain the desired quality and precision of the deformed ring. Wang [20] proposed a process virtualization with a program based on an optimization of objective functions whose target is to control the motion of the Guide and Axial rolls. A mathematical model of the ring stiffness condition for Radial Axial Ring Rolling was established by Hua [21] based on the stiffness model, by introducing a control method of the pressure in the hydraulic cylinder to adjust the guiding force. Yang [22] developed a method to control the Guide rolls by the hydraulic adjustment mechanism with a 3D-FE Ring Rolling model, based on the optimal parameter design of the linkage assembly and critical pressure of the hydraulic ram. Wang enhanced the Guide roll control by implementing ANSYS Parametric Design Language Program [23]. However, despite all mentioned ongoing researches that give great contribution to the process knowledge, some limits still exist especially for the milling curve design and in particular for the influence of the Idle and Axial speed laws. Moreover, another lack of knowledge is still recorded about the approach used to analyze the output results that does not take into account some parameters such as form tolerances that are critical from an industrial point of view.

Usually, in an industrial environment, the trend is to machine with few basic milling curves designed as function of the aspect ratio (height/width) of the starting/final ring cross section. In particular, the curves shape (that could be concave or convex) depends on the aspect ratio that could be higher or lower than 1 . These basic milling curves are integrated in a system software in terms of percentage and are scaled as a function of the initial and final ring dimensions. For a specified ring geometry, the basic milling curve undergoes to little modifications that take into account the ring weight, 
the working temperature, material and process vibration. During the process, the mill control software monitors the ring deformation with two main controls: a laser measuring the external diameter expansion and the Axial roll displacement using the integrated encoder. When a significant difference of the measured and estimated parameters occurs, the machine reduces the Idle and Axial rolls speed (in terms of percentage). Moreover, it must be underlined that during the equalizing phase the closed loop control integrated in the machine, based on the mentioned measuring system, could increase the equalizing time to reach the final geometries. The length of this step is correlated with how the imposed milling curve is able to correctly deform the ring cross section. However, despite these controls, the operator modifies in real time the Idle or Axial roll displacement to compensate environment variables as the room temperature, perform geometry variation, rolls wear, etc.

The need of all these modifications is due to a starting basic milling curve that does not guarantee stable conditions and to the integrated software that is able to monitor only a localized part of the ring evolution: one point for the external diameter and the height only in the Axial rolls gap.

Moreover, even with these procedures, the produced rings are characterized by a geometrical error in terms of dimensions (diameter, height and width) and form properties (circularity, roundness and flatness). To reduce waste production, a higher stock allowance is considered in the preform design that is time and cost consuming for the following machining/finishing step. It is important to report that form errors make difficult the machining step introducing problems as self-centering (circularity and roundness) or vibrations (flatness).

Another important aspect is related to the production time that is important not only for an optimization of the rolling process, but it also affects former production steps as preform upsetting. In particular, the dwell time of the billet in oven before the upsetting step is highly affecting the rolling production time. For the preform production, several billets are uploaded in an oven to reach the forging temperature for the following steps (upsetting, punching and rolling), once the temperature is reached, there is a maintenance time that depends on how fast the rolling machine deforms the preform.

Based on this scenario, to enhance the knowledge about the influence of the milling curve on the ring production and looking for an optimized milling curve, in this paper the authors designed and tested different Idle and Axial speed profiles. The research was conducted considering an industrial case, simulating it with finite element modeling and then validating the model by comparing experimental observations and simulation results. Results allowed to identify different Idle and Axial speed profiles able to produce a more precise ring with reduced maximum loads or with short production time compared to the industrial case.

\section{MATERIALS AND METHODS}

As discussed in the introduction, this work starts from an industrial case and tests different rolls speed profiles to optimize them. To validate the model, geometrical ring parameters and milling load values were identified. In particular, the ring height $(\mathrm{H})$, width $(\mathrm{W})$ and external diameter $\left(\mathrm{D}_{\text {ext }}\right)$ have been selected as geometrical parameters while the maximum Idle Load ( $\left.\mathrm{F}_{\mathrm{Y}_{-} \text {Idle }}\right)$ and the maximum Axial Load $\left(\mathrm{F}_{\mathrm{Z}_{-} \text {Axial }}\right)$ have been chosen as milling parameters. All the experimental data were reproduced on the ring rolling machine at LA LEONESSA Spa (Figure 3).

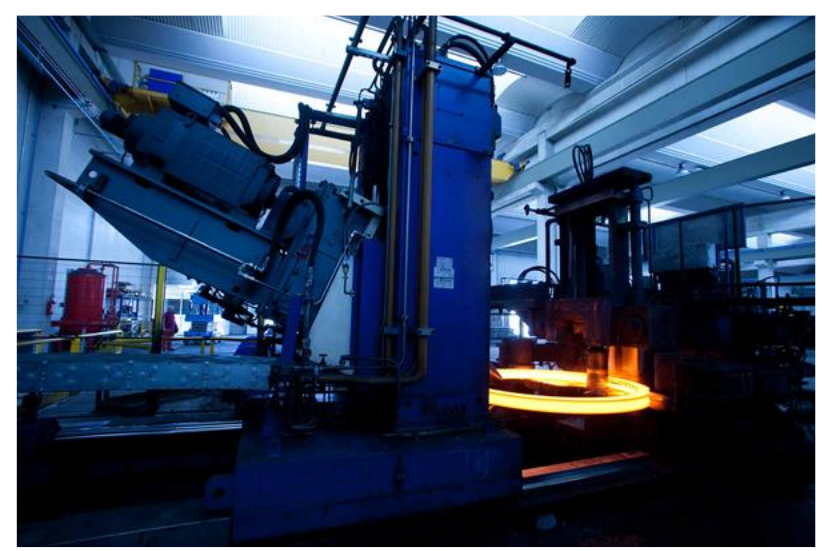

Figure 3. Ring rolling machine.

\section{Experimental Set Up}

The main dimensions of the ring and characteristics of the rolling plant considered in the present research are summarized in Table 1 and 2; it could be observed that the Preform and Finished Ring volume are different. In particular, at the end of the process the ring volume is reduced by $8 \%$, this reduction is given by the material lost during the deformation due to the oxidation that occurs while the billet is heated in the oven. 
Table 1. Ring dimension and characteristics.

\begin{tabular}{llll}
\hline Parameter & H & W & D $_{\text {ext }}$ \\
\hline Preform [mm] & 75 & 69 & 258 \\
Finished Ring [mm] & 56 & 50 & 373 \\
Material & AISI 1045 & \\
Initial Workpiece Temperature & 1150 & & \\
{$\left[{ }^{\circ} \mathrm{C}\right]$} & 26.8 & & \\
Milling time [s] & &
\end{tabular}

Table 2. Rolls dimension and characteristics.

\begin{tabular}{lc}
\hline Parameter & Value \\
\hline Idle Roll Diameter[mm] & 110 \\
Driving Roll Diameter [mm] & 700 \\
Driving Roll angular velocity [rad/sec] & 3.35 \\
Axial Roll Height [mm] & 400 \\
Axial Roll taper angle $\left[^{\circ}\right]$ & 15.7 \\
\hline
\end{tabular}

The software supervising the industrial milling process controls the milling curve, the Driving roll angular velocity and the Axial roll Y-speed as input parameters. The machine is equipped with a laser system able to measure in real time the ring diameter expansion, while the height reduction is controlled by the encoder equipped on the Axial roll. Based on the milling curve and on the real time measurements, the software can control and instantaneously modify the rolls speed profile. As discussed in the introduction, Figures $4 \mathrm{a}$ and $4 \mathrm{~b}$ report the Idle roll Y-speed and Axial roll Z-speed profiles respectively as modified by the software for the analyzed industrial case. As it can be observed, the software imposed a decreasing trend to the Idle Roll speed profile and a parabolic trend for the Axial roll. In order to obtain the milling curve, the Idle roll speed and Axial roll speed have been integrated; the resulting function is the Idle roll and Axial roll stroke in function of time.

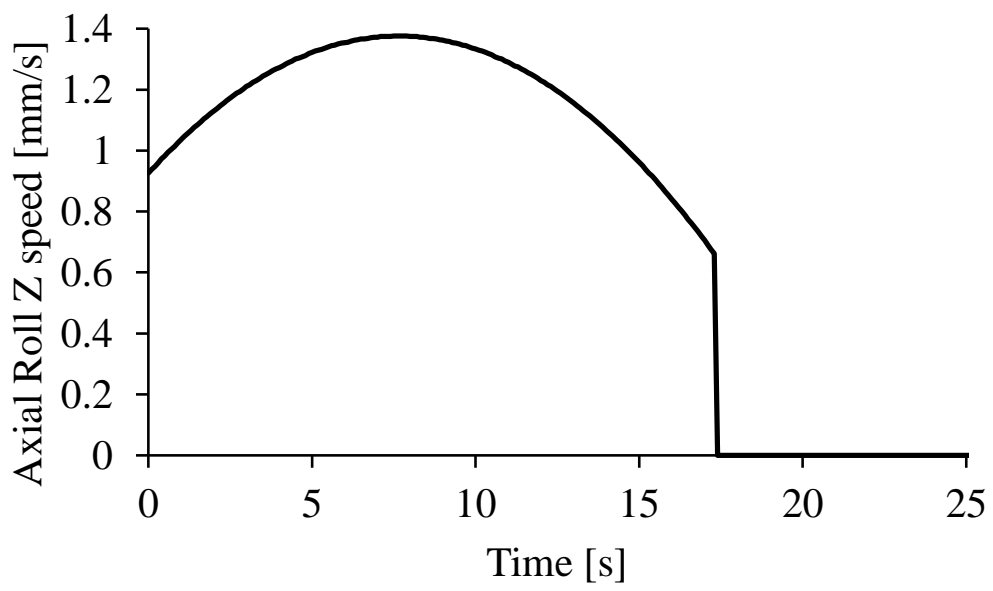

(a)

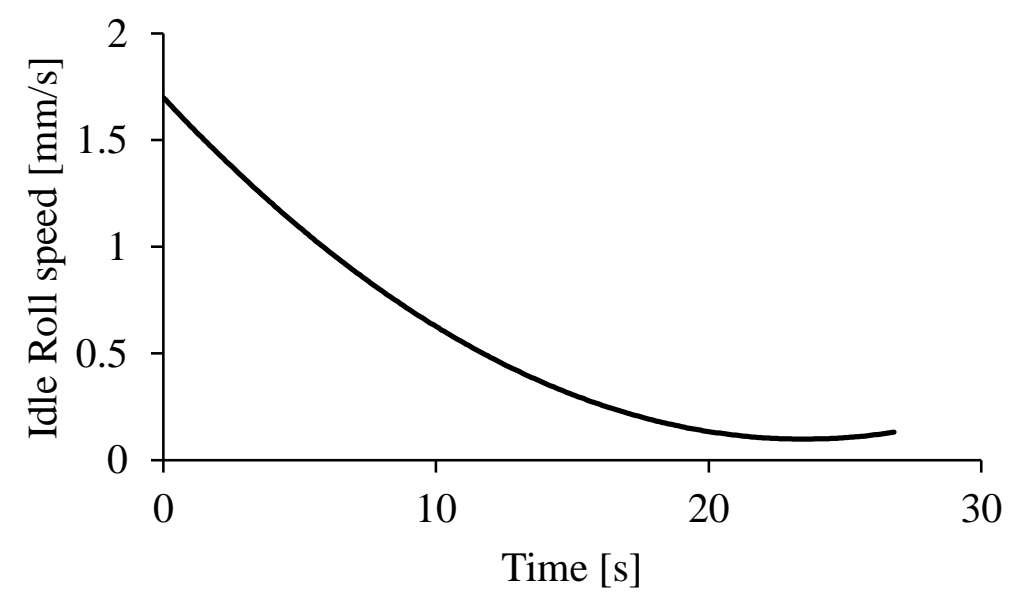

(b)

Figure 4. Experimental (a) idle roll Y-speed profile and (b) axial roll Z-speed profile. 
The machine is equipped with different load cells able to measure and monitor the loads acting on the Idle and the Axial rolls. In addition, the authors measured the ring geometrical parameters at the end of the process.

\section{Numerical Model Set Up}

In the present paper Ring Rolling Deform 3D subroutine produced by SFTC was used to simulate the industrial case study. This new subroutine decreases the computational time in days instead of weeks. The authors successfully tested in previous works the software robustness by a geometrical and loads point of view [24-25]. The Ring Rolling subroutine utilizes an Arbitrary Lagrangian Eulerian (ALE) solver with automated time stepping. The ALE approach is an attempt to combine the advantages of the Eulerian and Lagrangian formulation methods. In the ALE formulation, a reference system is defined such that coordinates are neither fixed in space nor attached to the material. This Computational Reference System (CRS) is used in conjunction with a second reference system, the Material Reference System (MRS) behaving as a Lagrangian mesh. The ALE formulation permits the independent mesh movement in the CRS, which in turn allows the use of a non-uniform mesh with element concentration in the roll gap regions [26]. The following constrains characterizes the subroutine: The software works with a hybrid mesh method (Figure 5) defining a finer area of elements in correspondence of the area in contact with the rolls. The hybrid mesh method was initially proposed by Hu et al. [27] incorporating a graded computational mesh and a separate, uniformly fine material mesh. The computational mesh is constructed as a subset of the material mesh and it is used in the finite-element computations. Within the main deformation regions, a finer mesh is available and a one-to-one correspondence between elements and nodes of the material mesh and those of the computational mesh is achieved. On the contrary, to reduce mesh element and computational time, outside the radial deformation zones, the position and state variable values are interpolated from the coarse computational mesh using conventional shape functions [28]. The remeshing strategy reduces the element distortions and maintains a high-quality mesh throughout the simulation. The software, thanks to self-centering properties, allows to simulate the process without the Guide rolls [29]. The rolls are considered rigid bodies.

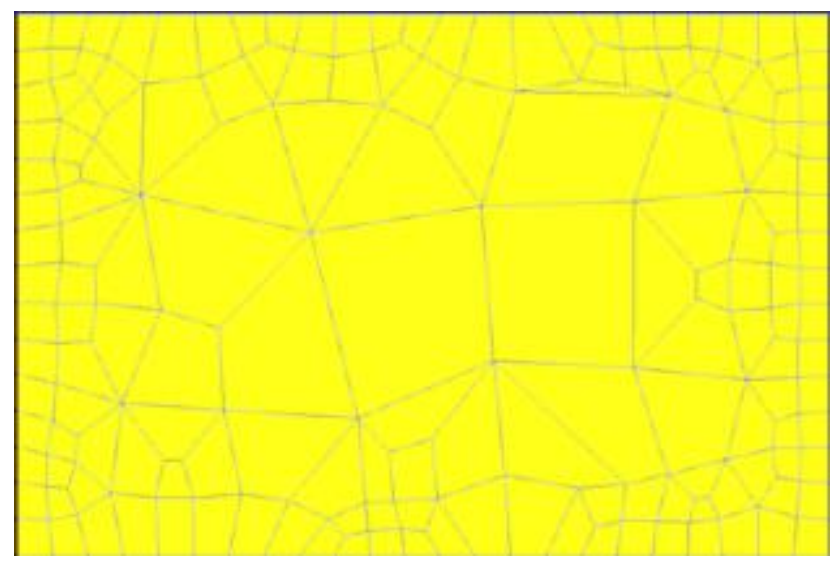

Figure 5. Hybrid mesh distribution method.

The FEM software allows to track the point coordinates during the deformation process so that it is possible to measure height, width and external diameter of the ring during the process. The ALE solver avoids possible errors in the parameters calculation due to the surface ring deformation [30]. As shown in Figure 6, three points have been defined to track the geometrical ring features.

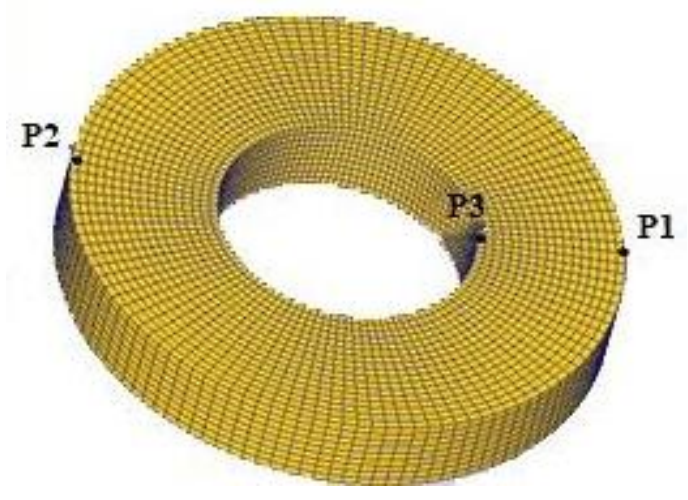

Figure 6. Points selected for coordinate tracking.

The following Equations. (1) - (3) are used to evaluate the ring external diameter, width and height respectively: 


$$
\begin{gathered}
D_{\text {ext }}=\sqrt{\left(X_{1}-X_{2}\right)^{2}+\left(Y_{1}-Y_{2}\right)^{2}} \\
W=\sqrt{\left(X_{1}-X_{3}\right)^{2}+\left(Y_{1}-Y_{3}\right)^{2}} \\
H=Z_{3}
\end{gathered}
$$

Finally, the graphs of the load acting on each roll as a function of the rolling time or as a function of the roll strokes, have been used for the milling load values estimation. Starting from these FE input assumptions two different set of simulations have been designed. The first set of five simulations (FEM model design) were executed to select the appropriate model simplification to reduce the simulation time; in particular symmetry, isothermal and automatic axial roll displacement on Y axis have been tested. Table 3 summarizes the model constrain.

Table 3. Constraint setting of the five tests.

\begin{tabular}{rccc}
\hline Model & Symmetry & Isothermal & Axial Roll displacement on Y axis \\
\hline Test 1 & Yes & Yes & Manually \\
Test 2 & Yes & Yes & Automatic \\
Test 3 & Yes & No & Automatic \\
Test 4 & No & Yes & Automatic \\
Test 5 & No & No & Automatic \\
\hline
\end{tabular}

Based on FEM model design results the second set of simulations (FEM model optimization) was executed. In these simulations the logic used to design the Idle and Axial speed profiles was to set a profile with constant motion on the $\mathrm{Y}$ axis for the Idle roll and a profile with increasing linear motion on the $\mathrm{Z}$ axis for the Axial roll. The authors set these assumptions after previous researches [31-34] where different Idle and Axial speed profiles have been analyzed and tested. The Idle roll speed $\mathrm{V}_{\mathrm{W}}$ profile has been designed simply dividing the Idle roll stroke by the rolling time; the Axial roll velocity (namely $\mathrm{V}_{\mathrm{H}}$ ) was calculated as a function of the starting $\left(\mathrm{H}_{\mathrm{i}}\right)$ and finish $\left(\mathrm{H}_{\mathrm{f}}\right)$ ring height and of the process time ( $\left.\mathrm{t}_{\text {process }}\right)$. Equations. (4 a-d) define the Idle and Axial roll speed laws:

$$
\begin{gathered}
V_{W}=\frac{W_{i}-W_{f}}{t_{\text {process }}} \\
V_{H}=m t+q \\
m=\frac{H_{i}-H_{f}}{t_{\text {process }}^{2}} \\
q=\frac{H_{i}-H_{f}}{2 t_{\text {process }}}
\end{gathered}
$$

Based on Equations. 4(a-d) different six simulations have been designed with a decreasing production time to optimize the process. In Figure 7, a flow chart of the optimization strategy is reported. 


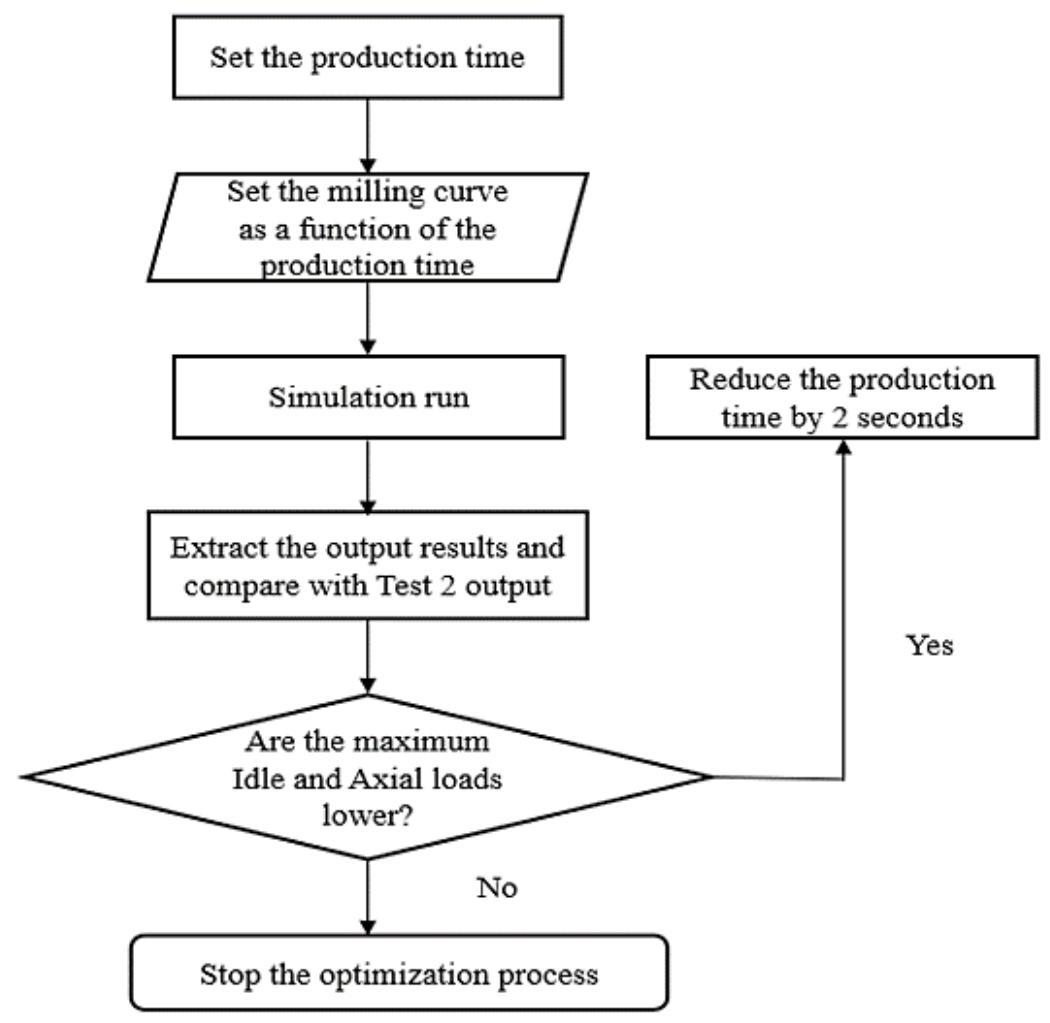

Figure 7. Optimization strategy flowchart.

According to this approach, six new FEM models were designed obtaining a process time reduction ranging between $5 \%$ and $37 \%$. Table 4 summarizes all the input parameters to evaluate the Idle and Axial roll speed laws for the simulated tests.

Table 4. Input parameters for the idle and axial speed laws.

\begin{tabular}{ccccccc}
\hline & & & \multicolumn{4}{c}{$\mathrm{V}_{\mathrm{H}}[\mathrm{mm} / \mathrm{s}]$} \\
\hline & $\begin{array}{c}\mathrm{t}_{\text {process }} \\
{[\mathrm{s}]}\end{array}$ & $\begin{array}{c}\mathrm{V}_{\mathrm{w}} \\
{[\mathrm{mm} / \mathrm{s}]}\end{array}$ & $\mathrm{m}$ & $\mathrm{q}$ & $\begin{array}{c}\mathrm{V}_{\mathrm{Hi}} \\
{[\mathrm{mm} / \mathrm{s}]}\end{array}$ & $\mathrm{V}_{\mathrm{Hf}}[\mathrm{mm} / \mathrm{s}]$ \\
\hline TEST A & 26.8 & 0.709 & 0.026 & 0.354 & 0.354 & 1.063 \\
TEST B & 24.8 & 0.766 & 0.031 & 0.383 & 0.383 & 1.149 \\
TEST C & 22.8 & 0.833 & 0.037 & 0.417 & 0.417 & 1.250 \\
TEST D & 20.8 & 0.913 & 0.044 & 0.457 & 0.457 & 1.370 \\
TEST E & 18.8 & 1.011 & 0.054 & 0.505 & 0.505 & 1.516 \\
TEST F & 16.8 & 1.131 & 0.067 & 0.565 & 0.565 & 1.696 \\
\hline
\end{tabular}

\section{Industrial Validation Set Up}

More significant results of the FEM model optimization simulations have been checked experimentally in industrial environment. For each test, three replicas were produced. The software implemented in the Ring Rolling machine requires the following process parameters: the milling curve, the Driving Roll angular velocity and the Axial Roll Y-speed profile for the backward roll displacement. The milling curves were evaluated by the Idle Y-speed and Axial Z-speed profiles; the Driving roll angular velocity was set constant and coherent with Table 2. The Axial Y-speed profile has been designed according to the following criteria: For each test the discrete diameter expansion as a function of the rolling time was extrapolated by the numerical models; a regression model was evaluated from external diameter numerical data; the regression model was derived for obtaining the diameter expansion speed profile; this new regression model was used to extrapolate the input point needed by the machine software to evaluate the Axial $\mathrm{Y}$-speed profile. Figures $8 \mathrm{a}$ and $8 \mathrm{~b}$ report, as an example, the diameter expansion and the Axial roll Y-speed profile for Test A. 


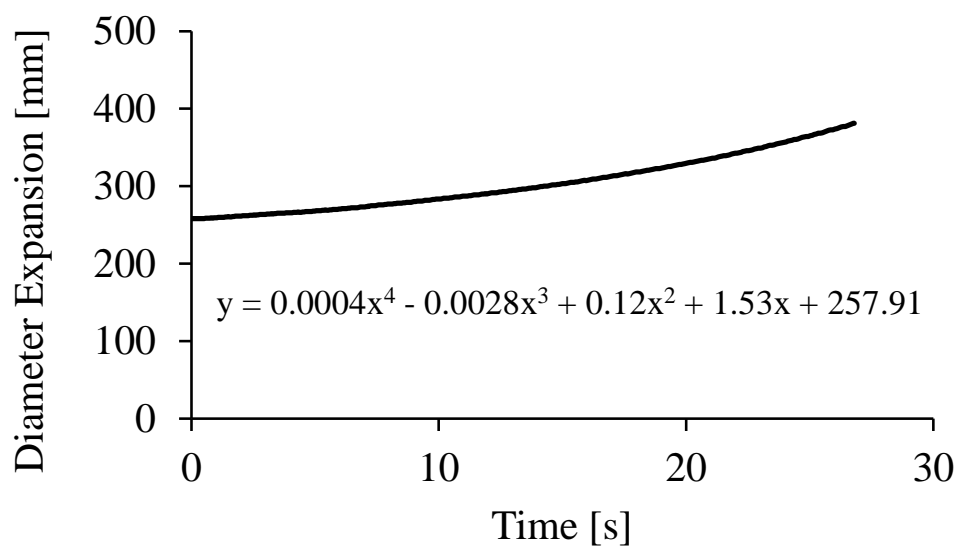

Figure 8(a). Diameter expansion.

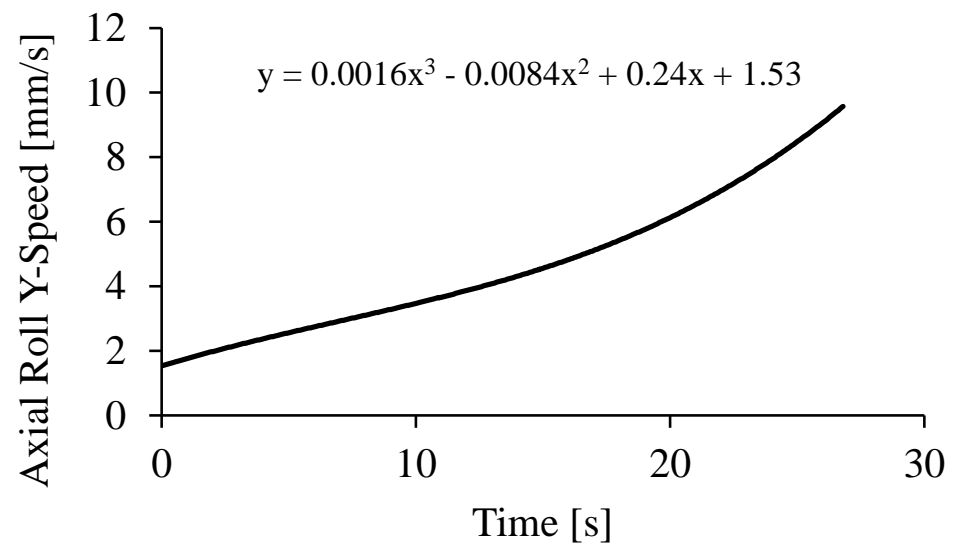

Figure 8(b). Axial roll Y-speed profile.

\section{RESULTS AND DISCUSSION}

The main results are presented into three different sub chapters. In the first sub chapter, the authors tested and compared different FEM models (Test 1 to Test 5) with the experimental process; in the second sub chapter, different Axial and Idle speed profiles were simulated by the identified FEM model (Test A to Test F). In the last sub chapter, the authors validated the most significant FEM results in the industrial environment (Test A EXP to test F EXP). To analyze the results, the authors assumed to reach an optimum accuracy if the difference is lower than 5\% and good when it is lower than $10 \%$. In the FEM validation results, reported in section 3.3, the authors assumed as significant an improvement in a range of about $10 \%$ and good when the improvement is higher.

\section{FEM Model Design Results}

Tables 5 and 6 report the most significant experimental and numerical results; their comparison is reported in terms of percentage deviation. The experimental measurements are referred to a mean value and a standard deviation estimated on ten produced rings. For the Axial and Radial loads, the comparison was based on the maximum value reached during the deformation process. In Table 7 the simulation time $\left(\mathrm{t}_{\mathrm{sim}}\right)$ was added too.

Table 5. Experimental and numerical results.

\begin{tabular}{|c|c|c|c|c|c|}
\hline \multirow[b]{2}{*}{ Test } & \multirow[b]{2}{*}{$\mathrm{D}_{\mathrm{ext}}[\mathrm{mm}]$} & \multirow[b]{2}{*}{$\mathrm{W}[\mathrm{mm}]$} & \multirow[b]{2}{*}{$\mathrm{H}[\mathrm{mm}]$} & \multicolumn{2}{|c|}{ Maximum Load } \\
\hline & & & & $\mathrm{F}_{\mathrm{Y}_{-} \text {Idle }}[\mathrm{N}]$ & $\mathrm{F}_{\mathrm{Z}_{-} \text {Axial }}[\mathrm{N}]$ \\
\hline $\operatorname{EXP} \mu(\sigma)$ & $378.6(0.2)$ & $50.0(0.1)$ & $55.0(0.1)$ & $1.8 \mathrm{E}+05(4.1 \mathrm{E}+03)$ & $\begin{array}{c}1.8 \mathrm{E}+05 \\
(8.0 \mathrm{E}+03)\end{array}$ \\
\hline Test 1 & 386.3 & 53.8 & 55.0 & $1.9 \mathrm{E}+05$ & $1.8 \mathrm{E}+05$ \\
\hline Test 2 & 386.1 & 53.8 & 55.0 & $1.9 \mathrm{E}+05$ & $1.7 \mathrm{E}+05$ \\
\hline Test 3 & 386.6 & 53.8 & 55.0 & $1.8 \mathrm{E}+05$ & $1.7 \mathrm{E}+05$ \\
\hline Test 4 & 386.3 & 53.8 & 55.0 & $1.8 \mathrm{E}+05$ & $1.8 \mathrm{E}+05$ \\
\hline Test 5 & 386.5 & 53.7 & 54.5 & $1.7 \mathrm{E}+05$ & $1.7 \mathrm{E}+05$ \\
\hline
\end{tabular}


Table 6. Percentage comparison between experimental and numerical results.

\begin{tabular}{ccccccc}
\hline & \multicolumn{3}{c}{ Maximum Load } \\
\hline Test & $\begin{array}{c}\mathrm{t}_{\text {simulation }} \\
{[\mathrm{s}]}\end{array}$ & $\begin{array}{c}\mathrm{D}_{\text {ext }} \\
{[\mathrm{mm}]}\end{array}$ & $\begin{array}{c}\mathrm{W} \\
{[\mathrm{mm}]}\end{array}$ & $\begin{array}{c}\mathrm{H} \\
{[\mathrm{mm}]}\end{array}$ & $\begin{array}{c}\text { FY_Idle } \\
{[\mathrm{N}]}\end{array}$ & F $_{\text {Z_Axial }}[\mathrm{N}]$ \\
\hline Test 1 & 78 & $-2.0 \%$ & $-7.6 \%$ & $-0.1 \%$ & $-3.9 \%$ & $0.8 \%$ \\
Test 2 & 300 & $-1.9 \%$ & $-7.6 \%$ & $0.0 \%$ & $-4.0 \%$ & $3.5 \%$ \\
Test 3 & 870 & $-2.1 \%$ & $-7.6 \%$ & $0.1 \%$ & $0.6 \%$ & $5.3 \%$ \\
Test 4 & 600 & $-2.0 \%$ & $-7.6 \%$ & $-0.1 \%$ & $-2.2 \%$ & $-2.7 \%$ \\
Test 5 & 960 & $-2.1 \%$ & $-7.5 \%$ & $0.8 \%$ & $4.5 \%$ & $4.5 \%$ \\
\hline
\end{tabular}

As shown in Table 6 all models can forecast the external diameter and ring height with an optimal accuracy $(<5 \%)$, and the ring width with a good accuracy $(7.5 \%)$. The decrease of performance for the ring width forecasting can be explained considering that Deform software does not include the loss of material during the deformation. The accuracy for the milling load variables is in a range between $1 \%$ and $6 \%$. The comparison of the results indicates that all the models can simulate the industrial case with a good accuracy. Obviously, the time needed to simulate the process highly decreases if symmetry and isothermal conditions are imposed (Test 1 and 2). In addition, even if Test 1 is the model with lower simulation time (78 $\mathrm{min}$ ) Test 2 is more coherent with the industrial situation due to the automatic backward displacement on the $\mathrm{Y}$ axis of the Axial roll. Based on these considerations the authors selected Test 2 as reference model for the optimization tests.

\section{FEM Model Optimization Results}

The output results and the percentages comparison with Test 2 are reported in Tables 7 and 8, respectively.

Table 7. New FEM models results.

\begin{tabular}{cccccccc}
\hline & & & & & \multicolumn{3}{c}{ Maximum Load } \\
\hline & $\begin{array}{c}\mathrm{t}_{\text {process }} \\
{[\mathrm{s}]}\end{array}$ & $\begin{array}{c}\mathrm{t}_{\text {simulation }} \\
{[\mathrm{min}]}\end{array}$ & $\begin{array}{c}\mathrm{D}_{\text {ext }} \\
{[\mathrm{mm}]}\end{array}$ & $\begin{array}{c}\mathrm{W} \\
{[\mathrm{mm}]}\end{array}$ & $\begin{array}{c}\mathrm{H} \\
{[\mathrm{mm}]}\end{array}$ & $\mathrm{F}_{\mathrm{Y} \_ \text {Idle }}[\mathrm{N}]$ & $\begin{array}{c}\mathrm{F}_{Z_{\_} \text {Axial }} \\
{[\mathrm{N}]}\end{array}$ \\
\hline Test 2 & 26.8 & 300 & 386.1 & 53.8 & 55.0 & $1.9 \mathrm{E}+05$ & $1.8 \mathrm{E}+05$ \\
Test A & 26.8 & 240 & 381.3 & 54.7 & 55.3 & $1.6 \mathrm{E}+05$ & $1.6 \mathrm{E}+05$ \\
Test B & 24.8 & 205 & 380.4 & 55.0 & 55.7 & $1.6 \mathrm{E}+05$ & $1.6 \mathrm{E}+05$ \\
Test C & 22.8 & 120 & 379.2 & 55.2 & 55.4 & $1.6 \mathrm{E}+05$ & $1.7 \mathrm{E}+05$ \\
Test D & 20.8 & 240 & 378.2 & 55.7 & 55.7 & $1.7 \mathrm{E}+05$ & $1.7 \mathrm{E}+05$ \\
Test E & 18.8 & 300 & 378.3 & 55.0 & 55.2 & $1.7 \mathrm{E}+05$ & $1.9 \mathrm{E}+05$ \\
Test F & 16.8 & 250 & 378.0 & 55.4 & 55.7 & $1.8 \mathrm{E}+05$ & $1.9 \mathrm{E}+05$ \\
\hline
\end{tabular}

Table 8. Percentage comparison between Test 2 and new FEM models.

\begin{tabular}{lccccccc}
\hline & & & & & \multicolumn{2}{c}{ Maximum Load } \\
\hline Test A & $0.0 \%$ & $-20 \%$ & $-1.2 \%$ & $1.6 \%$ & $0.6 \%$ & $-17.1 \%$ & $-13.3 \%$ \\
Test B & $-7.5 \%$ & $-32 \%$ & $-1.5 \%$ & $2.2 \%$ & $1.4 \%$ & $-16.6 \%$ & $-10.9 \%$ \\
Test C & $-14.9 \%$ & $-60 \%$ & $-1.8 \%$ & $2.7 \%$ & $0.8 \%$ & $-16.3 \%$ & $-5.3 \%$ \\
Test D & $-22.4 \%$ & $-20 \%$ & $-2.0 \%$ & $3.5 \%$ & $1.2 \%$ & $-11.1 \%$ & $-5.4 \%$ \\
Test E & $-29.9 \%$ & $0 \%$ & $-2.0 \%$ & $2.2 \%$ & $0.4 \%$ & $-10.5 \%$ & $4.1 \%$ \\
Test F & $-37.3 \%$ & $-17 \%$ & $-2.1 \%$ & $2.9 \%$ & $1.3 \%$ & $-4.5 \%$ & $4.8 \%$ \\
\hline
\end{tabular}

Table 8 clearly shows how all the tested FEM models can reproduce the ring with a good geometrical quality. As expected, the maximum Idle and Axial load values have a growing trend proportional to the rolling time reduction. Furthermore, the results show that different roll speed profiles can be implemented as a function of the optimization goal. If the industrial need is to realize a ring with lower loads, Test A is a good solution; on the opposite if the goal is the reduction of the rolling time, test $\mathrm{F}$ can be considered an appropriate solution. Test D is, instead, a good compromise between a significant reduction of time $(-22 \%)$ and loads. Regarding the computational time, it is possible to notice that all the tests have been simulated quite quickly ( $\max 300 \mathrm{~min}$ ).

The previous considerations are evident in the graphs shown in Figures 9(a) and 9(b) where the external diameter and the maximum loads are compared as a function of the simulated tests. From these graphs Test D could be target as the break-even point between geometry and loads. 


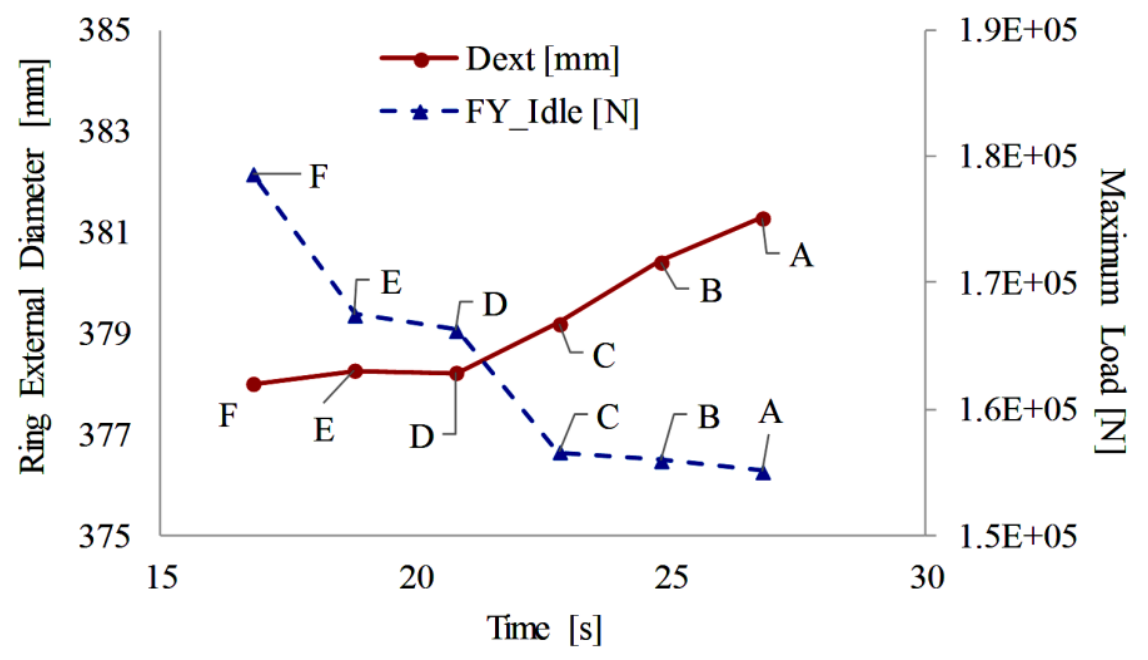

(a)

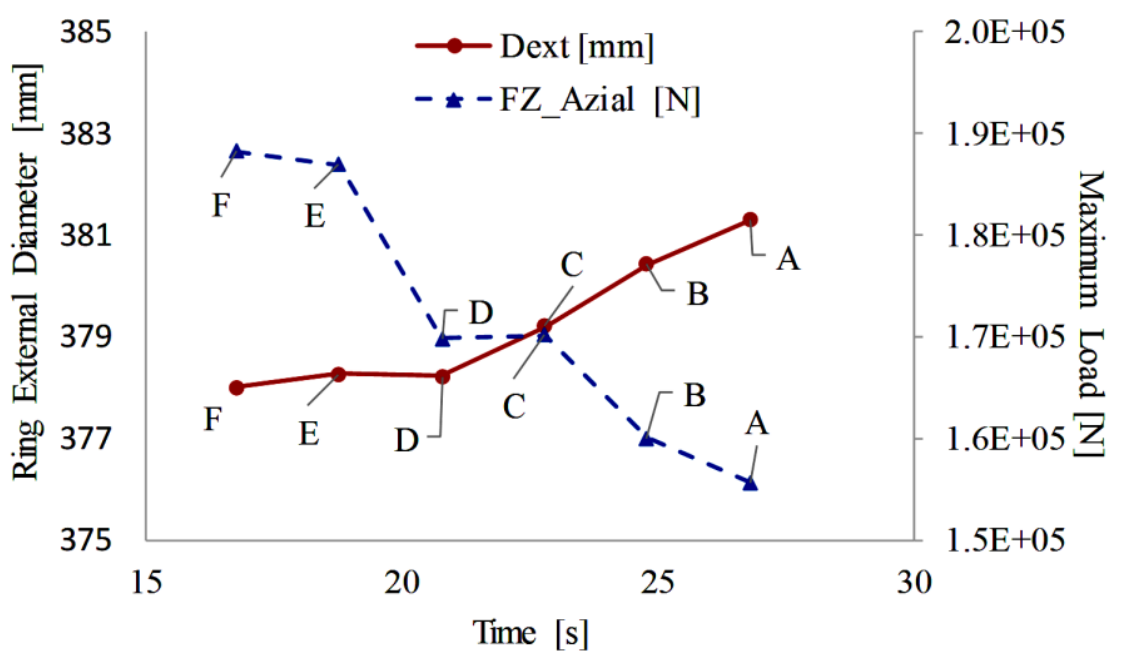

(b)

Figure 9. The plot of ring external diameter against (a) idle maximum load and (b) axial maximum load.

Industrial Validation of FEM Results

Tables 9 and 10 report the main results, in terms of mean values and standard deviations, for the experimental Tests $\mathrm{A}, \mathrm{D}$ and $\mathrm{F}$ and the percentage deviation with respect to the original process configuration (EXP).

Table 9. New experimental results.

\begin{tabular}{|c|c|c|c|c|c|c|}
\hline & & & & & \multicolumn{2}{|c|}{ Maximum Load } \\
\hline & $\mathrm{t}_{\text {process }}[\mathrm{s}]$ & $\mathrm{D}_{\mathrm{ext}}[\mathrm{mm}]$ & $\mathrm{W}[\mathrm{mm}]$ & $\mathrm{H}[\mathrm{mm}]$ & $\mathrm{F}_{\mathrm{Y} \_ \text {Idle }}[\mathrm{N}]$ & $\mathrm{F}_{\mathrm{Z} \_ \text {Axial }}[\mathrm{N}]$ \\
\hline EXP & 26.8 & $378.7(0.3)$ & $\begin{array}{l}50.0 \\
(0.1)\end{array}$ & $\begin{array}{l}55.0 \\
(0.2)\end{array}$ & $1.8 \mathrm{E}+05(5.3 \mathrm{E}+03)$ & $1.8 \mathrm{E}+05(7.2 \mathrm{E}+03)$ \\
\hline Test A EXP & 26.8 & $375.9(0.2)$ & $\begin{array}{l}49.4 \\
(0.1)\end{array}$ & $\begin{array}{l}58.2 \\
(0.1)\end{array}$ & $1.6 \mathrm{E}+05(8.4 \mathrm{E}+02)$ & $1.7 \mathrm{E}+05(6.6 \mathrm{E}+03)$ \\
\hline Test D EXP & 20.8 & $376.0(0.1)$ & $\begin{array}{l}49.6 \\
(0.2)\end{array}$ & $\begin{array}{l}58.5 \\
(0.2)\end{array}$ & $1.7 \mathrm{E}+05(2.3 \mathrm{E}+03)$ & $1.8 \mathrm{E}+05(9.8 \mathrm{E}+03$ \\
\hline Test F EXP & 16.8 & $375.2(0.3)$ & $\begin{array}{l}49.1 \\
(0.1)\end{array}$ & $\begin{array}{l}58.0 \\
(0.2)\end{array}$ & $1.8 \mathrm{E}+05(6.7 \mathrm{E}+03)$ & $1.8 \mathrm{E}+05(7.6 \mathrm{E}+03)$ \\
\hline
\end{tabular}


Table 10. Percentage comparison between Test 2 and new experimental results.

\begin{tabular}{lcccccc}
\hline & & & \multicolumn{3}{c}{ Maximum Load } \\
\hline & $\mathrm{t}_{\text {process }}[\mathrm{s}]$ & $\mathrm{D}_{\text {ext }}[\mathrm{mm}]$ & $\mathrm{W}[\mathrm{mm}]$ & $\mathrm{H}[\mathrm{mm}]$ & $\mathrm{F}_{\mathrm{Y} \text { Idle }}[\mathrm{N}]$ & $\mathrm{F}_{\mathrm{Z} \text { Axial }}[\mathrm{N}]$ \\
\hline Test A EXP & $0.0 \%$ & $-0.7 \%$ & $-1.2 \%$ & $5.8 \%$ & $-8.7 \%$ & $-6.7 \%$ \\
Test D EXP & $-22.4 \%$ & $-0.7 \%$ & $-0.8 \%$ & $6.4 \%$ & $-6.9 \%$ & $-0.7 \%$ \\
Test F EXP & $-37.3 \%$ & $-0.9 \%$ & $-1.8 \%$ & $5.5 \%$ & $-2.6 \%$ & $-1.7 \%$ \\
\hline
\end{tabular}

Analyzing Tables 9 and 10, it is possible to observe that all the tests produce good quality rings, but the experiments did not confirm the loads reduction forecasted by the numerical simulation as reported in Table 7 . The main problem is due to the simplification that the mill control software applies to the Axial roll Y-speed equation. As can be observed in Figure 8(b), the regression model found is quite complex and the mill software is not able to perfectly follow the equation. This limit affects the backward displacement of the Axial roll and causes the reported difference between the experimental and numerical values. Despite this incongruence, a significant load reduction is recorded for each test. Indeed, Table 10 highlights that the ring geometries are still in the required range with respect to EXP configuration and that the times needed to produce the rings are significantly decreased. To have a more detailed geometric comparison, a 3D scanner with structured light (Cronos 3D) was used to acquire the produced ring geometries (STL file). Using a metrological software (GOM inspect), the scanned rings have been compared with the 3D CAD geometry. Figure 10 shows the comparison of the four produced rings in which the acquired geometry has been compared with the CAD file; the red color refers to the parts of the geometry that are above the CAD file, while the blue color is for the data inside the CAD file. while Figure 11 illustrates the histograms of the errors deviation. The CAD dimensions refer to the nominal ring geometry and are reported in Table 1.

Table 9 shows that Test A EXP, D EXP and F EXP have an outer diameter closer to the desired value; the ring heights are bigger than the CAD ones for all the four cases, but better than for the EXP test (actual industry production). Analyzing the data related to the errors distribution reported in Figures 10 and 11, it can be concluded that Tests A EXP and F EXP have error deviations contained in a smaller range with respect to EXP and D EXP test. Moreover, to completely analyze the obtained ring geometries, the dimensional and geometrical tolerances were compared too. Tables 11 and 12 report the measured data (mean and standard deviation) and percentage differences with respect to EXP showing an improvement of the external circularity and flatness for all rings produced with the new roll speed profile. The ring roundness is worse in the case of Test A EXP, equal for Test D EXP and better for the Test F EXP.

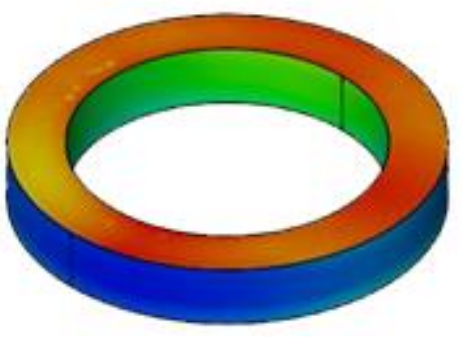

(a) EXP

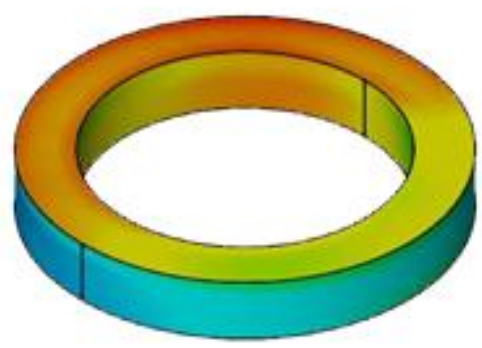

(c) TEST D EXP

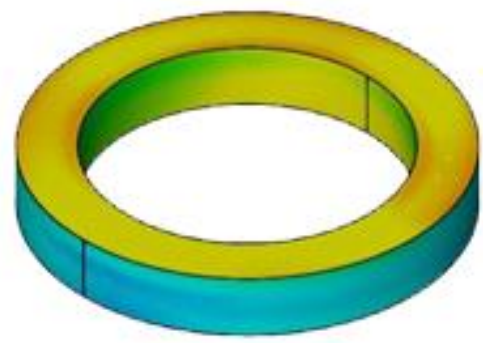

(b) TEST A EXP

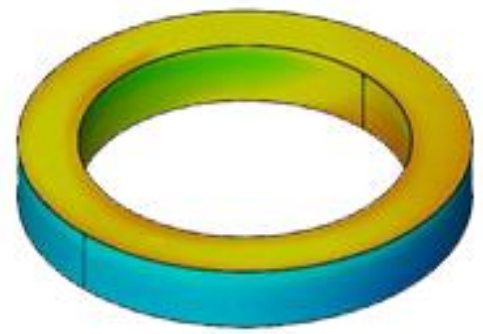

(d) TEST F EXP

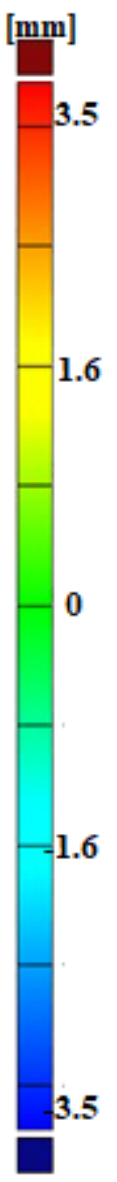

Figure 10. Comparison between acquired STL and CAD geometries [in mm]. 


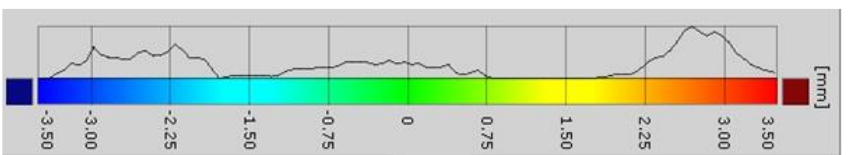

(a) EXP

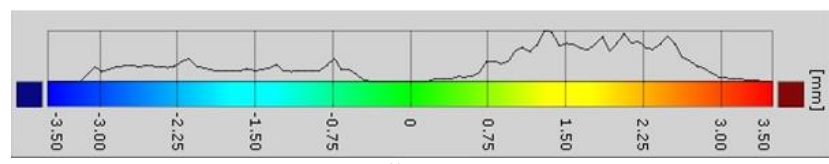

(c) TEST D EXP

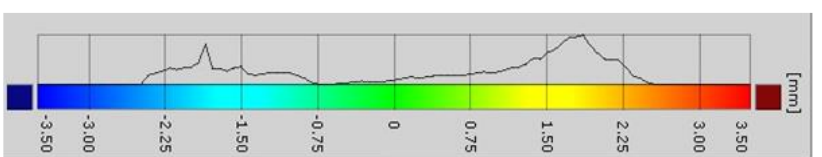

(b) TEST A EXP

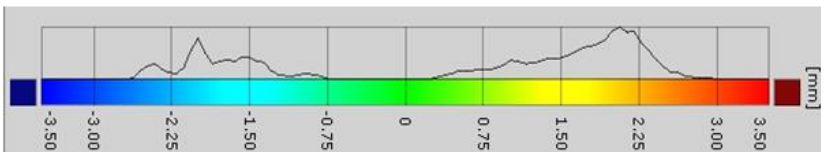

(d) TEST F EXP

Figure 11. Histogram of error deviation.

Table 11. Geometrical tolerances measured on the experimental results [in mm].

\begin{tabular}{cccc}
\hline & External circularity & Flatness lower surface & Roundness \\
\hline Test EXP & $0.94(0.08)$ & $1.50(0.10)$ & $0.87(0.03)$ \\
Test A EXP & $0.50(0.05)$ & $1.48(0.07)$ & $1.20(0.04)$ \\
Test D EXP & $0.59(0.06)$ & $1.10(0.09)$ & $0.90(0.03)$ \\
Test F EXP & $0.57(0.06)$ & $1.20(0.11)$ & $0.70(0.04)$ \\
\hline
\end{tabular}

Table 12. Percentage comparison of geometrical tolerances.

\begin{tabular}{cccc}
\hline & External circularity & Flatness lower surface & Roundness \\
\hline Test A EXP & $-46.81 \%$ & $-1.33 \%$ & $37.93 \%$ \\
Test D EXP & $-37.23 \%$ & $-26.67 \%$ & $3.45 \%$ \\
Test F EXP & $-39.36 \%$ & $-20.00 \%$ & $-19.54 \%$ \\
\hline
\end{tabular}

\section{CONCLUSIONS}

In this paper, the authors proposed a method for optimizing the Ring Rolling process combining experimental and simulation analysis. The method has proved to be effective when applied to an industrial case by implementing a customized milling curve based on new Idle and Axial speed profiles to reduce process time. The FEM approach has been validated by experimental results. From the results it is possible to see that a significant reduction of the maximum loads required for rolling (about 10\%) at a constant production time can be obtained by implementing constant and linear equations for the Idle Roll and the Axial Roll speed profile; moreover a significant reduction of the production time (about $40 \%$ ) can be achieved keeping constant the required loads constant when using the new speed profiles. The most interesting simulation results were validated in the industrial environment confirming the forecasted production time reductions. These results produced an improvement in ring tolerances in terms of roundness, flatness and circularity with respect to the industrial case study was highlighted too. This was considered by the company a very good improvement since it allows to obtain better ring quality in the finishing operations without machine vibrations and with reduced tool wear.

\section{ACKNOWLEDGEMENTS}

The authors thank La LEONESSA Spa and in particular Ing. Giacomo Zanetti for the help, support and availability given during the entire process of testing and data acquisition.

\section{REFERENCES}

[1] Eruc E, Shivpuri R. A summary of Ring Rolling technology - Recent trends in machines, processes and production lines. International Journal of Machine Tools and Manufacturing. 1992; 32:379-98.

[2] Allwood JM, Tekkaya AE, Stanistreet TF. The development of Ring Rolling technology. Steel Research International. 2005; 76:111-20.

[3] Giorleo L, Ceretti E, Giardini C. Investigation of the Fishtail Defect in Ring Rolling by a FEM Approach. Proceedings of NAMRI/SME 40: Notre Dame, Indiana, USA. 2012.

[4] Zhou G, Hua L, Qian D. 3D coupled thermo-mechanical FE analysis of roll size effects on the radial-axial Ring Rolling process. Computational Materials Science. 2011; 50:911-924.

[5] Salem M, Heydari M. A new approach in modelling of guide and conical rolls in the Ring Rolling process. The International Journal of Advanced Manufacturing Technology. 2015; 81:1831-1843.

[6] Giorleo L, Ceretti E, Giardini C. Energy consumption reduction in Ring Rolling processes: A FEM analysis. International Journal of Mechanical Sciences. 2013; 74:55-64. 
[7] $\mathrm{Ng} \mathrm{CH}$, Lai CF, Yahaya SNM, Shamsudin S, Ahmad SNAS, Sharrifuddin F. Effect of initial blank temperature in hot press forming towards 22MnB5 springback failure. Journal of Mechanical Engineering and Sciences. 2019; 13:5137-5149.

[8] Mianroodi M, Altmeyer G, Touchal S. Experimental and numerical FEM-based determinations of forming limit diagrams of St14 mild steel based on Marciniak-Kuczynski model. Journal of Mechanical Engineering and Sciences. 2019; 13:5818-5831.

[9] Zhu X, Liu D, Yang Y, Hu Y, Liu G, Wang Y. Effects of blank dimension on forming characteristics during conical-section Ring Rolling of Inco718 alloy. International Journal of Advanced Manufacturing Technology. 2016; 84:2707-2718.

[10] Lin H, Zhi ZZ. The extremum parameters in Ring Rolling. Journal of Material Processing Technology. 1997; 69:273-276.

[11] Yan FL, Hua L, Wu YQ. Planning feed speed in cold Ring Rolling. International Journal of Machine Tools and Manufacturing. 2007; 47:1695-1701.

[12] Anjami N, Basti A. Investigation on constant and variable feed speeds effects in Ring Rolling process using 3D FEM. Advanced Materials Research. 2011; 264-265:1776-1781

[13] Guo L, Yang H. Towards a steady forming condition for radial-axial Ring Rolling. International Journal of Mechanical Sciences. 2011; 53:286-299.

[14] Peng WF, Niu BK, Zhang JH, Hong Z, Shu XD. A 3D-FEM of adaptive movement control of guide and conical rolls in Ring Rolling process. International Journal of Advanced Manufacturing Technology. 2017; 92:3287-3298.

[15] Zhou G, Hua L, Qian D, Shi D, Li H. Effects of axial rolls motions on radial-axial rolling process for large-scale alloy steel ring with 3D coupled thermo-mechanical FEA. International Journal of Mechanical Science. 2012; 59:1-7.

[16] Li L, Li X, Liu J, He Z. A quantitative planning method of variable feed rates for cold profiled Ring Rolling process. The International Journal of Advanced Manufacturing Technology. 2016; 86:2585-2593.

[17] Mohanty S, Regalla S, RaoY. Influence of process parameters on surface roughness and forming time of Al-1100 sheet in incremental sheet metal forming. Journal of Mechanical Engineering and Sciences. 2019; 13: 4911-4927

[18] Jenkouk V, Hirt G, Franzke M, Zhang T. Finite element analysis of the Ring Rolling process with integrated closed-loop control. CIRP Annals - Manufacturing Technology. 2012; 61:267-270.

[19] Li L, Li X, Liu J, He Z. Multi-response optimization design of parameters for cold Ring Rolling process using fuzzy-grey method. International Journal of Materials and Product Technology50. 2015; 2:101-123.

[20] Wang ZW, Fan JP, Hu DP, Tang CY, Tsui CP. Complete modelling and parameter optimization for virtual Ring Rolling. International Journal of Mechanical Sciences. 2010; 52:1325-33.

[21] Hua L, Deng J, Qian D, Lan J, Long H. Modeling and application of ring stiffness condition for radial-axial Ring Rolling. International Journal of Machine Tools \& Manufacture. 2016; 110:66-79.

[22] Li L, Yang H, Guo L, Sun Z. A control method of guide rolls in 3D-FE simulation of Ring Rolling. Journal of Material Processing Technology. 2008; 205:99-110.

[23] Wang ZW, Zeng SQ, Yang XH, Cheng C. The key technology and realization of virtual Ring Rolling. Journal of Material Process Technology. 2007; 182: 374-381.

[24] Giorleo L, Ceretti E, Giardini C. Validation of hot Ring Rolling industrial process 3D simulation. International Journal of Material Forming. 2013; 6:145-152.

[25] Ceretti E, Giardini C, Giorleo L. 3D simulation of a hot Ring Rolling industrial process. International Journal of Material Forming. 2010; 3:323-326.

[26] Davey K, Ward MJ. The practicalities of Ring Rolling simulation for profiled rings. Journal of Material Processing Technology. 2002; 125-126:619-625.

[27] Hu ZM, Pillinger I, Hartley P, McKenzie S, Spence PJ. Three-dimensional finite-element modelling of Ring Rolling, Journal of Material Processing Technology. 1994; 45:143-148.

[28] Lim T, Pillinger I, Hartley P. A finite-element simulation of profile Ring Rolling using a hybrid mesh model. Journal of Materials Processing Technology. 1998; 80-81:199-205.

[29] Jinn JT, Wu WT. Finite Element Modeling of Ring Rolling Processes. AIP Conference Proceedings. 2010; 1252:795-801.

[30] Bar-Yoseph, Mereu S, Chippada V, Kalro J. Automatic monitoring of element shape quality in 2-D and 3-D computational mesh dynamics. Computational Mechanics. 2001; 27:378-395.

[31] Giorleo L, Ceretti E, Giardini C. Speed Roll laws influence in a Ring Rolling process. Key Engineering Materials. 2013; 554557:337-344.

[32] Giorleo L, Ceretti E, Giardini C. Milling curves influence in Ring Rolling processes. Key Engineering Materials. 2014; 622623:956-963.

[33] Giorleo L, Ceretti E, Giardini C. Speed Idle Roll law optimization in a Ring Rolling process. Key Engineering Materials. 2015;651-653:248-253

[34] Giorleo L, Ceretti E, Giardini C. Idle and axial roll speed law trend effect in an industrial Ring Rolling process. AIP Conference Proceeding. 2016;1769:130006. 